\title{
RETENÇÃO DOS DISCENTES DE ADMINISTRAÇÃO DA UFS: FATORES CONDICIONANTES E AÇÕES DA GESTÃO ACADÊMICA
}

\author{
COLLEGE RETENTION OF THE ADMINISTRATION STUDENTS \\ OF UFS: REASONS AND ACADEMIC MANAGEMENT
}

\author{
Recebido em: 14/12/2015 A Aprovado em: 17/02/2016 \\ Avaliado pelo sistema double blind review \\ Editora Científica: Claudia Stadtlober \\ DOI 10.13058/raep.2016.v17n2.428
}

\author{
RODRIGO TELES DANTAS DE OLIVEIRA oliveira.rtd@gmail.com \\ JENNY DANTAS BARBOSA \\ UNIVERSIDADE FEDERAL DE SERGIPE
}

\begin{abstract}
RESUMO
Este artigo aborda a temática da retenção dos discentes de Administração da Universidade Federal de Sergipe (UFS), ou seja, a permanência dos alunos além do tempo regular. Os objetivos são: traçar as características dos alunos; identificar os motivos da retenção; mensurar o nível de qualidade do curso e conhecer as ações de combate à retenção desenvolvidas pelo Departamento de Administração. Os dados foram coletados por meio de pesquisa documental e bibliográfica; questionários do Google Forms ${ }^{\circledR}$ com os alunos retidos e entrevistas com os docentes que ocuparam o cargo de chefia do Departamento/Colegiado. Os dados quantitativos foram analisados utilizando-se estatística não paramétrica, com base em escalas adaptadas de Likert e tratados com o software SPSS ${ }^{\circledR}$. O tratamento das informações qualitativas se deu por meio de análise de conteúdo. Concluiu-se que a maioria dos alunos retidos é do gênero feminino, solteira, com faixa etária entre os i8 e 30 anos e renda de I a 3 salários mínimos. Trabalha e/ou estagia durante 40 ou mais horas/semana e possui mais de $75 \%$ do curso concluído. Os motivos da retenção são a falta de tempo; o choque entre as agendas profissional/acadêmica; as greves; a insatisfação com o corpo docente; e a reprovação/trancamento de disciplinas. Os alunos classificaram o curso como regular. A gestão da retenção pelo departamento tem sido feita de forma parcial.
\end{abstract}

Palavras-chave: Retenção universitária; Gestão da Educação; Ensino Superior.

\section{ABSTRACT}

This article discusses the subject of students retention from the Management Program of the Federal University of Sergipe (UFS), regarding the maintenance of the student beyond the regular time. The objectives of this article are to outline the characteristics of UFS's Management students, to identify the retention reasons, to measure the quality of the course, and to learn the actions to avoid students' retention, which were developed by the Management Program. Data were collected through documental research and bibliographic references. Google Forms $s^{\circledR}$ were used for the retention of the students, as well as interviews were performed with the teachers from the Program who had previously occupied the cargo of Head of the Program/Department. Quantitative data were analyzed using nonparametric statistics through the SPSS ${ }^{\circledR}$ statistical program, using the adapted Likert scale. Qualitative information was analyzed through content analysis. It was concluded that most of the retained students were female, single, aged between 18-30 years old, with 1-3 minimum income wages, within work shifts and/or under internships of 40 or more hours/week, and having more than $75 \%$ of the course completed. The reasons identified for the retention were the lack of time of the students, conflict between their professional/academic schedules; strikes; dissatisfaction with faculty members, and reprobation/locking disciplines. Students rated the course as regular. Retention management has been done partially by the Department.

Keywords: College retention; Education Management; Higher Education. 


\section{INTRODUÇÃO}

O Ensino Superior brasileiro vem sendo, na última década, objeto de grandes transformações. O advento do Programa de Apoio a Planos de Reestruturação e Expansão das Universidades Federais (REUNI), o Sistema de Seleção Unificada (sISU) e o sistema de cotas são algumas das recentes ações de apoio à expansão da comunidade universitária. Apesar desse cenário de desenvolvimento, o sistema de Ensino Superior no Brasil é afetado por graves problemáticas, com destaque para a retenção e a evasão discente.

O crescimento da oferta de vagas no Ensino Superior, nos últimos anos, tem sido acompanhado pelo abandono parcial ou total do curso pelos alunos (INEP, 20I3). Fenômenos comuns nas Instituições de Ensino Superior (IES), a retenção e a evasão diferenciam-se pelo aspecto temporal a elas inerente. A retenção se dá quando o discente posterga sua formação, atrasando a conclusão do curso. A evasão, por sua vez, caracteriza-se pelo abandono definitivo da graduação. Quando ocorrem nas instituições públicas, esses fenômenos se mostram ainda mais problemáticos. O aluno que efetua matrícula em disciplinas que não frequentará, apenas para garantir o vínculo acadêmico, onera os cofres públicos e não dá o retorno esperado à sociedade (CAMPELLO; LINS, 2008).

Os custos causados pelo abandono/atraso da graduação representam grande empecilho à eficiência na gestão universitária (FIALHO; PFEIFFER; PRESTES, 20I4). A previsão orçamentária das universidades toma como base, entre outros fatores, o número de alunos ativos na instituição. No caso das IES públicas, a evasão impacta os cofres públicos à medida que o orçamento é planejado para um contingente de alunos que, efetivamente, não estará ativo na instituição. A retenção, por sua vez, exige repasses financeiros além do esperado, já que a instituição é levada a manter toda uma estrutura física, tecnológica e de recursos humanos para atender um conjunto de discentes que permanecerá além do tempo regular.

A retenção e a evasão refletem disfunções, institucionais e/ ou pessoais, no processo de formação acadêmica do alunato. Do ponto de vista institucional, representa uma distorção do papel social das IES, que é, essencialmente, a formação profissional (ALENCAR, 20I4). No âmbito pessoal, os discentes 
retidos ou evadidos se afastam de forma gradual do curso em que estão matriculados, devido aos períodos de insatisfação e insegurança que vivenciam (PEREIRA JÚNIOR, 2OI2).

Os cursos de Administração foram responsáveis por aproximadamente II\% das matrículas do Ensino Superior brasileiro registradas no ano de 2013 (INEP, 20I3). Esse percentual mostra a importância do curso, bem como seu grau de atratividade para os ingressantes no terceiro grau.

Em detrimento a esse panorama, os índices de abandono da graduação em Administração no Brasil são preocupantes. No trabalho de Silva Filho et al. (2007), entre os anos de 200r e 2005, o curso deteve o sexto maior nível de evasão, com resultados na ordem de 30\%, em média. Cunha et al. (20I4), por sua vez, indicam que, de 200 a a 2010, a taxa de evasão dos cursos de Administração no Brasil alcançou 16,24\%.

O curso de Administração da Universidade Federal de Sergipe (UFs) acompanha a tendência percebida no âmbito nacional. O índice anual de diplomação mostra que muitos são os ingressantes e poucos os egressos. Em 2013, II9 alunos foram matriculados no curso, enquanto 70 se formaram, assim, resultando numa taxa de sucesso de apenas 58,3\% (UFs, 2013). Além disso, foi apurado, com o Departamento de Administração (DAD) da UFs, que, dos 8Io alunos ativos no curso (período 2015.I), 350 deles se encontravam com a graduação postergada, o que representa um índice de $43 \%$ de retenção. Esses dados caracterizam uma conjuntura conflitante sobre a real qualidade e eficiência do curso em questão.

A retenção e a evasão são importantes indicadores da qualidade e efetividade das políticas e dos métodos de ensino implementados pelas IES. Por serem fenômenos complexos, sua identificação e caracterização se fazem mister para o desenvolvimento do Ensino Superior. Portanto, as ações corretivas a serem desenvolvidas devem estar baseadas numa análise macroscópica do problema "abandono do curso", nesse sentido, objetivando a criação de um conjunto de medidas educacionais efetivas de combate ao abandono/atraso do curso.

Diante dessas observações, objetivou-se, com esta pesquisa, identificar as características dos alunos de Administração da Ufs que estão retidos; 
mensurar o nível de qualidade do curso, com base na opinião dos discentes; identificar os fatores condicionantes da retenção; e conhecer as ações de combate à retenção desenvolvidas pelos gestores do curso. A partir dessas informações, o planejamento e a execução de ações corretivas por parte da UFs, no âmbito institucional, e pelos alunos, individualmente, tornar-se-ão possíveis. 
FUNDAMENTAÇÃO TEÓRICA

Apresenta-se a revisão bibliográfica sobre o tema em questão, com isso, construindo o contexto basilar da presente pesquisa e dando-lhe consistência conceitual.

\section{A RETENÇÃO E A EVASÃO NO ENSINO SUPERIOR}

Vincent Tinto foi um dos primeiros estudiosos a debruçar-se sobre a questão do abandono da graduação. Seu modelo teórico, em parceria com Cullen (TINTO; CULLEN, I975), preconiza que as características pessoais dos universitários, como personalidade, estrutura familiar e evolução escolar, influenciam no grau de compromisso desses em concluir a graduação. Além disso, Tinto defende que as integrações acadêmica e social são fatores-chave para a permanência do aluno no Ensino Superior. O esforço pessoal e a relação entre instituição e aluno são outros aspectos abordados.

Para Tinto, o nível de envolvimento do discente nas atividades acadêmicas está amplamente ligado ao grau de dedicação conferido ao processo de ensino-aprendizagem. Sua proposta teórica mais recente, Classrooms as Communities (TINTO, I997), em atualização ao Modelo Teórico de Evasão da Universidade (TINTO; CULLEN, I975), relaciona as variáveis institucionais e individuais que influenciam no grau de esforço do discente, conforme apresentado na Figura I.

Quando as condições para a permanência regular no Ensino Superior apresentam rupturas, o engajamento discente não se dá de forma plena. A distorção do papel das comunidades acadêmica e externa, também, exerce influência nesse processo. É nesse contexto que a evasão se manifesta. 
Figura I Relação entre estrutura institucional, aprendizado e persistência

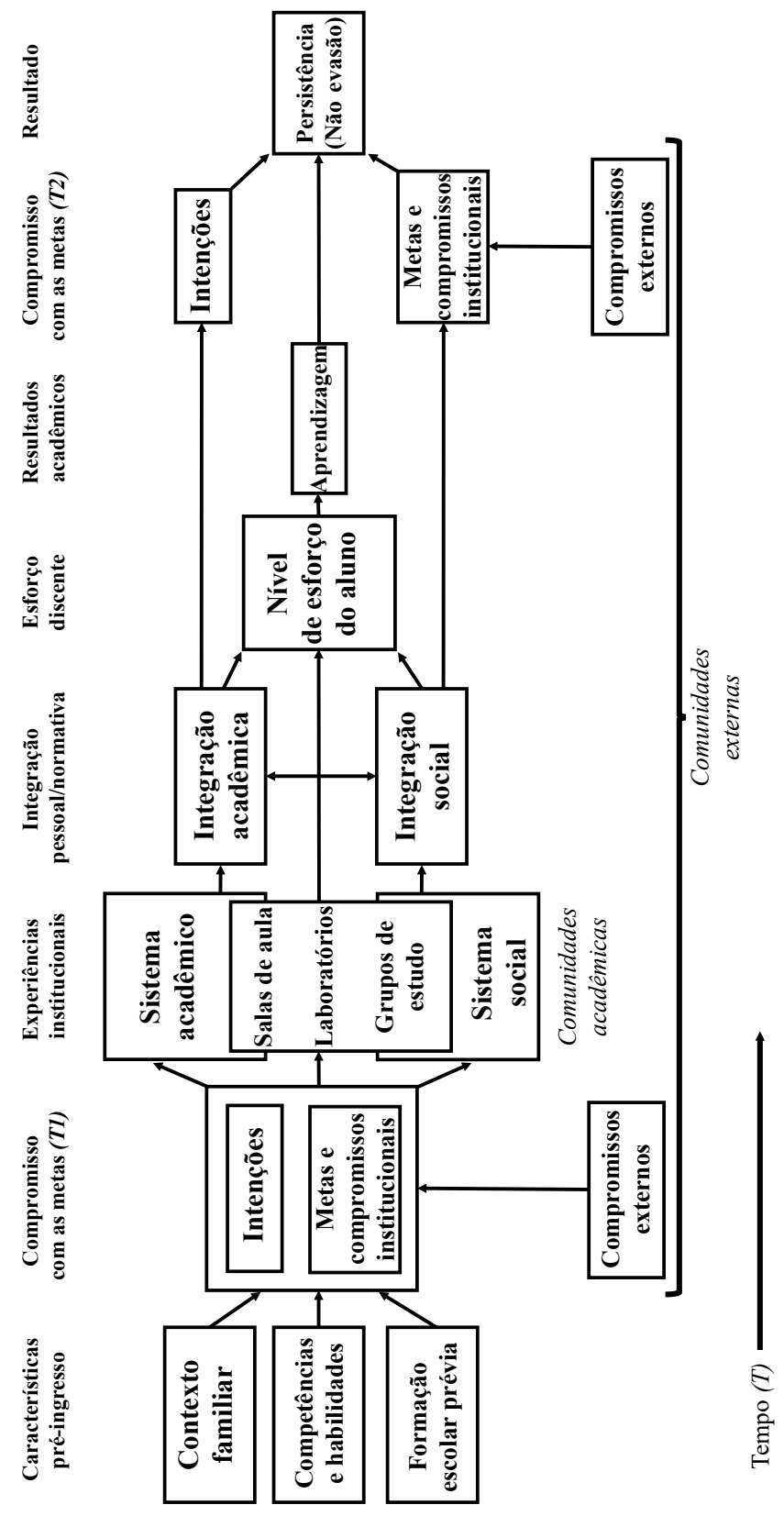

Fonte: Tinto (1997) - Tradução nossa. 
Em pesquisa sobre a permanência universitária, Tinto (1996) apresenta, ainda, sete motivos condicionantes para a evasão do ensino superior, a saber:

- Dificuldades acadêmicas: baixo desempenho, habilidades estudantis insuficientes e dificuldade em organizar os estudos.

- Dificuldades na adaptação: ocorrem quando o aluno não consegue lidar com as cobranças inerentes à transição para o ensino superior.

- Objetivos: podem ser incertos, quando não há um planejamento da evolução acadêmica e de carreira; estreitos, quando a inserção no curso não objetiva a conclusão da graduação; ou novos, quando o aluno altera suas metas iniciais.

- Compromissos externos: obrigações pessoais ou profissionais que inviabilizam a continuidade dos estudos, de modo que ocorre uma interrupção temporária da graduação.

- Inadequação financeira: o discente desestimula-se ao perceber que seu investimento no curso não proporcionará o retorno financeiro esperado.

- Inadequação entre discente e IEs: há, nesse caso, divergências entre valores, expectativas, resultados e aprendizagem do aluno relativamente à instituição de ensino.

- Isolamento: o aluno não desenvolve contatos no âmbito acadêmico, causando sentimento de não pertencimento à comunidade acadêmica. No Brasil, as primeiras discussões sistemáticas acerca da evasão no Ensino Superior aconteceram na Comissão Especial de Estudos sobre a Evasão nas Universidades Públicas Brasileiras, em 1996. Promovido pela Secretaria de Educação Superior do Ministério da Educação e do Desporto (SESU/MEC), esse estudo coletivo conceitua a evasão como "a saída definitiva do aluno de seu curso de origem, sem concluí-lo” (COMISSÃo MEC, I996, p. I5). A partir dessa definição, a Comissão classifica a evasão em três tipos:

Evasão de curso: quando o estudante desliga-se do curso superior em situações diversas, tais como: abandono (deixa de matricular-se), desistência (oficial), transferência ou reopção (mudança de curso), exclusão por norma institucional; Evasão da instituição: quando o estudante desliga-se da instituição na qual está matriculado;

Evasão do sistema: quanto o estudante abandona de forma definitiva ou temporária o ensino superior. (COMISSÃo MEC, 1996, p. 16). 
Gaioso (2005), por sua vez, cita a evasão como interrupção no ciclo de estudos. Outro conceito para a evasão seria "o cancelamento da matrícula por opção própria do aluno ou por ato administrativo" (CORRÊA; NORONHA; SANTOS, 2003, p. 4). Portanto, a evasão corresponde ao afastamento do discente do curso e/ ou instituição de ensino ao qual está vinculado.

Silva Filho et al. (2007) descrevem a evasão sob dois aspectos. O primeiro, dito "evasão anual média", estima a percentagem de discentes matriculados em um sistema de ensino, IES ou curso que, não tendo alcançado a diplomação, também, não efetuou matrícula no ano/semestre seguinte. O segundo modelo, a "evasão total", mede o número de alunos que não obteve a diplomação após um determinado número de anos / períodos.

Esse último aspecto é tratado, por outros autores, como retenção. De acordo com Silva e Vasconcelos (20II), a retenção é entendida como a permanência do aluno no curso em que está matriculado, após um número de anos e/ou períodos superior ao planejado pelo currículo de determinada instituição. $\mathrm{O}$ presente estudo se debruça sobre esse tipo de abandono da graduação.

A retenção e a evasão são problemáticas graves que limitam a efetiva expansão da educação superior. Para Alencar (2014), o fenômeno da evasão se configura como um rompimento do papel social atrelado ao ensino universitário porque a formação acadêmica e profissional, razão de sua existência, não está sendo oferecida em plenitude. Silva Filho et al. (2007) classificam o desperdício causado pela evasão como um problema social, acadêmico e econômico, tendo em vista que culmina em ociosidade de recursos humanos, materiais e patrimoniais.

Diversos autores buscaram compreender os motivos que levam os discentes a afastarem-se da graduação. Polydoro (2000) sustenta, em sua pesquisa, que o trancamento de matrícula é um fator relevante para a evasão no Ensino Superior, tendo sido o principal motivo do abandono da graduação numa IEs de São Paulo. Entre os fatores inerentes ao trancamento de matrícula, o autor encontrou: falta de suporte financeiro, inserção no mercado de trabalho e falta de integração acadêmica.

No trabalho de Gaioso (2005), os motivos para o abandono do curso revelaram-se pela falta de orientação vocacional, pela imaturidade do aluno, 
pelas reprovações em disciplinas, pelas restrições financeiras, pela falta de perspectiva no mercado de trabalho, pela ausência de laços afetivos na universidade, pelo ingresso na faculdade por imposição familiar, entre outros.

Já Alencar (20I4), em sua recente pesquisa, aponta que a necessidade de trabalhar, a descoberta de uma carreira mais adequada, o choque entre os horários de trabalho e estudo, a escolha precoce da carreira e a falta de orientação institucional são os principais fatores para o abandono do ensino superior.

As limitações financeiras, também, figuram entre os motivos da evasão. Porém, Silva Filho et al. (2007) observam que restringir o afastamento do aluno da graduação aos fatores socioeconômicos representa uma simplificação, pois outros fatores, como questões de ordem acadêmica, expectativas com relação à formação e à integração com a IEs, igualmente, determinam o grau de estímulo para concluir o curso.

Diante desse panorama, a evasão e retenção podem ser caracterizadas como problemas complexos que exigem um diagnóstico minucioso de seus vários fatores determinantes, muitas vezes, voláteis, no ambiente onde são observadas.

\section{EVOLUÇÃO E CONSEQUÊNCIAS DA EVASÃO E RETENÇÃO NO BRASIL}

O Instituto Nacional de Estudos e Pesquisas Educacionais Anísio Teixeira (INEP) divulga, periodicamente, os índices da educação superior no Brasil. Relatórios como o Censo da Educação Superior e a Sinopse da Educação Superior são compostos por dados como o número de matrículas, alunos ingressantes, concluintes e outros. Essas informações baseiam o estudo da conjuntura do Ensino Superior no país.

Silva Filho (20I4) reuniu tais dados para elaborar um panorama da evasão ao longo de uma década. No Gráfico I, percebe-se que a evolução da evasão se mostra oscilante, apesar de não apresentar grandes discrepâncias entre os diferentes anos analisados. Isso reflete o declínio na efetividade das políticas de combate à evasão, visto que, em 2013, a taxa de evasão voltou a atingir um elevado patamar, tal como registrado em 2004. 
Gráfico I Evolução da Evasão nas IES públicas 2004-20I3

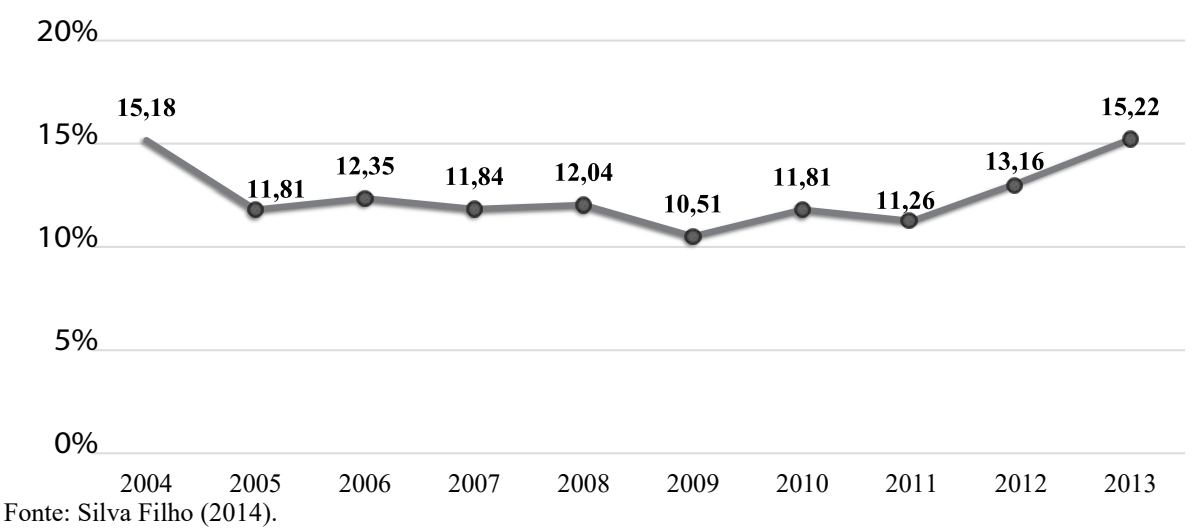

Apesar de usufruir de certa autonomia administrativa, a gestão das IES públicas sofre as restrições inerentes aos órgãos públicos. Seus orçamentos são altamente condicionados pelos índices por elas apresentados. O número de alunos matriculados, ingressantes e concluintes forma a base do cálculo de suas previsões orçamentárias anuais. A retenção e a evasão acarretam, além da não formação acadêmica dos alunos, impactos financeiros que afetam gravemente a gestão universitária (FIALHO; PFEIFFER; PRESTES, 20I4).

\section{EVASÃO NA UFS}

A problemática da evasão discente não conta com estudos sistemáticos no âmbito da UFs. Os dados mais elaborados acerca desse tema são puramente descritivos, divulgados em seus Anuários Estatísticos, que reúnem, entre outros, os números da movimentação dos discentes entre ingressantes, concluintes e evadidos. De acordo com os Anuários Estatísticos (UFs/ COPAC, 20II, 20I3) e o relatório da Coordenação de Planejamento e Avaliação Acadêmica (COPAC), a evasão na ufs (Campus São Cristóvão) está distribuída tal como no Gráfico 2. 
Gráfico 2 Evolução da Evasão na UFS 2009 - 2014

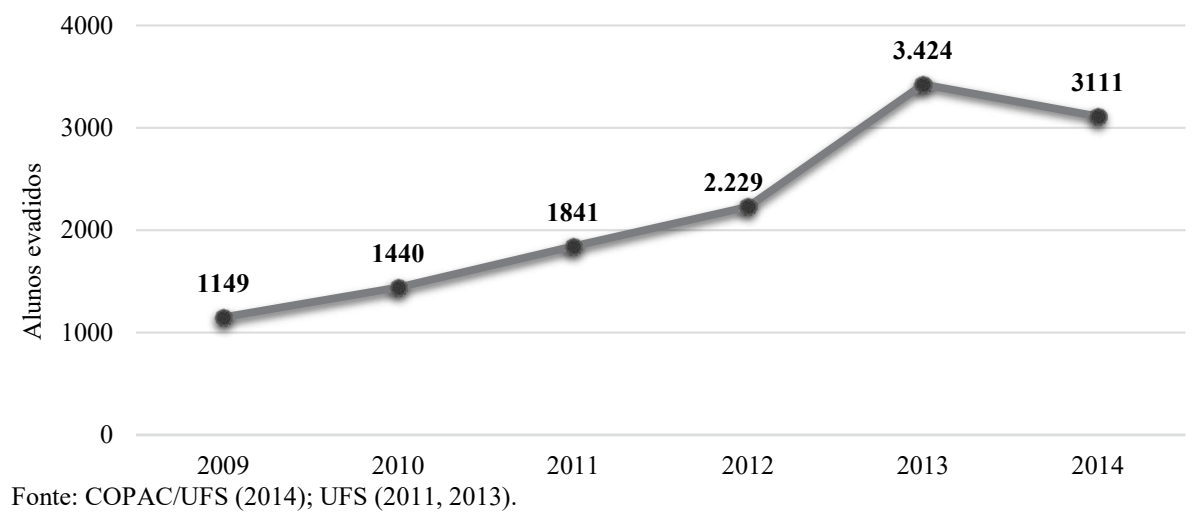

Ao analisar os números apresentados no Gráfico 2, percebe-se o crescimento exponencial da taxa de evasão na UFs, que alcançou $298 \%$ de 2009 a 2013. Esses resultados não satisfazem uma das diretrizes firmadas pela aprovação do REUNI na instituição: redução das taxas de evasão (UFS/CONEPE, 2008). Entre 2012 e 20I3, especialmente, o aumento da taxa de evasão foi expressivo. É importante ressaltar a ocorrência da greve dos docentes da UFs, iniciada em II de junho e encerrada em 24 de setembro de 20I2. Os três meses e meio de movimento grevista podem ter contribuído para o afastamento alguns dos alunos, que, com a suspensão das aulas, perdem o objetivo das atividades acadêmicas. A partir de 2013, houve uma pequena redução no número de alunos evadidos. Porém, ainda não é possível afirmar que a evasão segue uma tendência de decréscimo, conclusão que exigiria um maior número de resultados da evasão anual.

Entre as ações de combate à evasão, a UFs oferece os programas de Assistência Estudantil, a exemplo das bolsas alimentação, transporte e residência. No tocante às vagas ociosas, tem publicado, periodicamente, editais para o seu devido preenchimento, assim, atraindo diplomados, estudantes de outras instituições e ex-alunos (UFS / COGEPLAN, 20I5).

No entanto, como mostram os dados, a evasão ainda se mostra persistente na uFs. Tais ações são insuficientes para dirimir o problema, que necessita de uma abordagem sistemática para o seu combate, especialmente no tocante às causas do abandono do ensino superior. 


\section{METODOLOGIA}

O presente estudo apresenta natureza descritiva, pois entre os seus objetivos está a identificação dos motivos que levam ao prolongamento do curso e o delineamento das características dos alunos retidos do curso de Administração da ufs. Para Vergara (1998), a pesquisa descritiva, além de caracterizar uma determinada população e/ou fenômeno, possibilita a definição de sua natureza a partir da correlação de suas variáveis.

Adotou-se, como estratégia de pesquisa, o método de estudo de caso, único e incorporado, a partir da classificação de Yin (200I). No tocante à abordagem, esta pesquisa é classificada como mista: quantitativa e qualitativa. No aspecto quantitativo, foram abordados o perfil dos discentes, o nível de qualidade do curso e os fatores contribuintes para retenção no curso. Qualitativamente, coletou-se a avaliação dos coordenadores do curso de Administração sobre o tema, bem como as impressões dos alunos acerca do curso e do problema da retenção.

Com relação aos critérios para seleção do caso, destaca-se a relevância que o curso de Administração da ufs desempenha nos contextos acadêmico e profissional de Sergipe. Além do pioneirismo no ensino de Administração, a UFs é a única instituição que oferece tal graduação de forma gratuita no estado, desse modo, contribuindo social e economicamente com a comunidade onde está inserida.

Dado esse contexto, buscou-se compreender a retenção discente por meio da análise das informações obtidas com: i) discentes do curso de Administração da ufs retidos no curso (ingressantes até 2010 e não concluintes da turma de 20II); 2) docentes ativos que já tenham assumido o cargo de chefe do Departamento/Colegiado do curso de Administração.

Os alunos que ingressaram até o ano de 2010 já se encontram em prolongamento do curso, ao passo que os ingressantes de 2011 que não concluíram em 2015 se encaminham para a mesma situação. Assim, buscouse a opinião dos alunos que ultrapassaram o tempo regular de conclusão da graduação (5 anos). No tocante aos docentes, participaram apenas os professores ativos que já ocuparam a coordenação do departamento e/ou 
presidiram o colegiado do curso. Tal direcionamento se deu para que as informações coletadas abrangessem diversas gestões do DAD, mas orientadas para sua atual conjuntura, dando ênfase às atividades de gestão universitária desenvolvidas.

Adotou-se como fontes de evidências primárias os questionários e as entrevistas semiestruturadas. Entre as fontes secundárias, têm-se os estudos realizados sobre o tema, os relatórios de gestão orçamentária e acadêmica da uFs, além dos relatórios de informações acadêmicas dos alunos, oriundos do Sistema Integrado de Gestão de Atividades Acadêmicas (sIGAA).

A coleta de dados se deu por meio de questionários aplicados aos discentes, elaborados eletronicamente, via Google Forms ${ }^{\circledR}$, e enviados para o endereço de correio eletrônico cadastrado no sigaA. Posteriormente, os questionários respondidos foram tabulados, eletronicamente, com o auxílio da ferramenta $S P S S^{\circledR}$. Quanto aos docentes, foram desenvolvidas entrevistas semiestruturadas, em que as informações coletadas foram tratadas por meio da análise de conteúdo.

Os questionários aplicados aos discentes possibilitaram uma ampla análise de seus pontos de vista. Foram identificados 350 alunos em situação de retenção acadêmica, aos quais foi encaminhado o questionário eletrônico. Destes, II6 submeteram suas respostas, o que representa $33 \%$ do total da amostra. Nesse instrumento de coleta de dados, foram abordadas tanto questões essencialmente quantitativas (perfil socioeconômico, nível de qualidade do curso), gerando resultados em escalas, quanto qualitativas (comentários sobre os motivos da retenção, opiniões sobre o papel da coordenação do curso), por meio das quais os alunos puderam se expressar livremente. Quanto aos docentes, as entrevistas semiestruturadas se apresentaram como a fonte de pesquisa ideal, em razão do número de participantes ( 6 docentes), bem como devido à ênfase dada às suas opiniões, muitas vezes, de caráter subjetivo, visto que foram dirigentes do DAD. 


\section{RESULTADOS}

As informações coletadas com os discentes e docentes do curso de Administração da Ufs foram analisadas e são apresentadas a seguir.

\section{OS DISCENTES DE ADMINISTRAÇÃO RETIDOS NA UFS}

A maioria dos alunos desta amostra com longa permanência no curso eram do gênero feminino (63\%), solteira $(68 \%)$ e na faixa etária de I8 a 30 anos $(72 \%)$. Outras pesquisas na mesma temática reverberam tal equilíbrio entre os gêneros, a exemplo dos trabalhos de Cunha, Durso e Nascimento (20I4) e do de Silva e Vasconcelos (20II), em que 50\% dos alunos de Ciências Contábeis são mulheres.

Os alunos eram oriundos e residentes, principalmente, da região metropolitana de Aracaju (66\%), onde moravam com os pais (46\%). O núcleo familiar da ligeira maioria (39\%) detinha de I a 3 salários mínimos, seguido de perto pelas famílias que percebendo de 4 a 6 salários mínimos (38\%). Tais índices se apresentam conforme os da pesquisa de Silva e Vasconcelos (20II), na qual predominou a renda de R\$500 a R\$1.500 (32\%).

Percentual expressivo dos discentes concluiu toda a sua educação básica em instituições de ensino privadas (29\%), acompanhado de perto pelo grupo de alunos que sempre estudou em escolas públicas (28\%). Os $43 \%$ restantes frequentaram ambas as redes de ensino. Esses números convergem aos encontrados por Dias, Lopes e Theóphilo (2010), em que $42 \%$ dos alunos frequentaram o ensino médio em escolas públicas e o mesmo percentual, em escolas privadas.

Maior montante dos alunos ( $47 \%$ ) não se inseriu em nenhum dos grupos do sistema de cotas, devido à inexistência dele quando do ingresso na UFs. A entrada no curso de Administração se deu, para a maioria dos alunos retidos (56\%), no ano de 2010.

A quase totalidade (9r\%) dos discentes trabalhava e/ou estagiava, desempenhando suas tarefas durante 40 ou mais horas semanais. Assim, a maioria $(57 \%)$ deles revelou pouco tempo para os estudos, dedicando apenas entre i e 5 horas por semana a esse fim. Resultados semelhantes foram 
encontrados por Coelho et al. (2013); Sauberlich (2012) e Silva e Vasconcelos (20II), em que $85 \%$; $78 \%$ e $95 \%$ dos alunos trabalhavam, respectivamente.

Por conseguinte, os alunos indicaram (56\%) que as disciplinas que mais lhe causaram dificuldades na integralização dos créditos foram as de Finanças, que exigem dedicação e prática. Alencar (2014) chegou à mesma conclusão, pois a maioria ( $55 \%$ ) dos alunos, também, estudava entre i e 5 horas semanalmente.

Tal cenário não afeta relevantemente o desempenho geral da maior parte $(60 \%)$ dos discentes, que revelou média geral ponderada entre 7,0 e 8,9 pontos. Sobre a evolução acadêmica, eles estavam, majoritariamente (54\%), com mais de $75 \%$ do curso concluído, o que possibilita, a partir do planejamento acadêmico, a integralização dos créditos num curto espaço de tempo.

Importante montante dos alunos (40,5\%) não tinha Administração como opção prioritária de curso, pretendendo se graduar em outra área. Desses, a maioria desejava cursar Direito.

Diante de tais características, é possível perceber que o corpo discente de Administração, apesar de jovem, possui relevante vínculo com a carreira profissional. A importância dada à profissão, muitas vezes, cria obstáculos à fluidez da experiência acadêmica, assim, ocasionando a retenção no curso. No entanto, na área de gestão, a experiência profissional é fator decisivo na evolução da carreira, o que torna a dedicação ao trabalho perfeitamente aceitável, e, até mesmo, recomendável.

Nesse ponto, o planejamento acadêmico, desde o início da graduação, é uma ferramenta valiosa para a conclusão no tempo ideal, unindo dedicação aos estudos a uma boa estruturação da grade de disciplinas ao longo dos períodos acadêmicos.

\section{AVALIAÇÃO DISCENTE DA QUALIDADE DO CURSO}

Os alunos avaliaram a qualidade do curso, envolvendo aspectos acadêmicos, estrutura física, tecnológica, recursos humanos e acervo bibliográfico. Eles classificaram os itens conforme apresentado no Quadro I. 
Quadro I Avaliação discente da qualidade do curso de Administração

\begin{tabular}{|l|l|}
\hline Variáveis da qualidade do curso & Avaliação discente \\
\hline Acervo da biblioteca & Bom \\
\hline Domínio teórico dos docentes & \\
\hline Relação entre alunos e docentes/DAA/DAD & Regular \\
\hline Didática e métodos de ensino dos docentes & \\
\hline Grade curricular & \\
\hline Estrutura física e equipamentos & Ruim \\
\hline Oferta de disciplinas & \\
\hline Promoção de atividades de extensão/projetos de pesquisa & \\
\hline Adequação da teoria à prática & \\
\hline Promoção de aulas práticas/visitas técnicas & \\
\hline
\end{tabular}

Entre as variáveis apresentadas, a melhor avaliada pelos alunos foi o domínio teórico dos docentes, considerado bom por $59 \%$ dos respondentes. Esse resultado indica a importância conferida pelos docentes à sua formação acadêmica, fator imprescindível para a qualidade do ensino.

Significativo percentual (52\%) dos alunos opinou que a relação entre as teorias administrativas disseminadas nas aulas e a prática no mercado é ruim ou péssima. Outros $28 \%$ consideraram-na regular; e $19 \%$, boa. Apenas I $\%$ a considerou excelente, sendo esse o item pior avaliado pelos discentes.

As lacunas entre a universidade e o mercado não são novidade, fato que se explica pela rápida transformação das técnicas de gestão, que, muitas vezes, não são acompanhadas no mesmo ritmo pela academia. Na pesquisa de Biazus (2004), a falta de associação entre a teoria e a prática foi o segundo motivo mais citado pelos alunos de Ciências Contábeis da Universidade Federal de Santa Maria (UfSM) e da Universidade Federal de Santa Catarina (UFSC) para a evasão.

Nenhum dos itens apresentados aos alunos obteve maioria de respostas "excelente" e/ou "péssima".

Infere-se, após análise dos aspectos de qualidade apresentados, que a graduação em Administração é, para seus usufrutuários (alunos), apenas regular, resposta majoritária ao maior número dos itens componentes da avaliação do curso. 
A partir desses dados foi possível conceber os pontos fortes e fracos da graduação em Administração da uFs. Munido dessas informações, torna-se possível, para O DAD, tomar iniciativas visando à resolução das deficiências apontadas pelos alunos. O objetivo da UFs e do DAD deve ser o desenvolvimento contínuo do curso de Administração, fazendo jus à importância que ele exerce no cenário do Ensino Superior em Sergipe, por ser pioneiro, público e gratuito.

\section{FATORES EXPLICATIVOS DA RETENÇÃO DISCENTE}

A indisponibilidade de tempo foi considerada importante ou muito importante para a retenção por massivo número de alunos (81\%), mormente, devido à dedicação ao trabalho. Em decorrência disso, o choque entre as agendas profissional e acadêmica foi mais um motivo relevante para o atraso da formatura, indicado como importante ou muito importante por $78 \%$ dos discentes. Assim, percebeu-se uma ampla dedicação à carreira profissional pelos alunos, o que afeta negativamente seu desempenho acadêmico.

Tal resultado se assemelha aos encontrados por Alencar (2014), apontado como principal motivo para a retenção, além dos de Coelho et al. (2013) e Mello et al. (20II), nos quais o choque de horários teve a segunda maior frequência entre os motivos para o prolongamento da graduação.

As greves foram consideradas um fator decisivo para o atraso na conclusão do curso para elevado percentual de respondentes (79\%). Apesar de ser um instrumento legítimo de luta da categoria docente e buscar melhorias, também, para os alunos, a maior problemática das greves consiste na baixa motivação causada pela interrupção do período letivo, de difícil recuperação na volta às aulas.

Os alunos também atribuíram a longa permanência no curso à insatisfação com o corpo docente, pois as técnicas de ensino adotadas pelos professores foram um fator importante ou muito importante para a retenção de $54 \%$ dos respondentes. A desmotivação dos professores foi amplamente indicada nos comentários dos alunos. Acompanhando esse cenário, os alunos de Ciências Contábeis da UFSM e UFSC indicaram, no trabalho de Biazus (2004), que o principal motivo para a evasão foi a "pouca motivação por parte dos professores". 
Esse índice gera preocupação porque os alunos têm, junto aos professores, os primeiros contatos com a Administração. Quando suas expectativas com relação aos docentes são frustradas, a desmotivação e o desinteresse pela área podem emergir.

A reprovação em disciplinas, também, está entre os principais motivos para a retenção e foi indicada como importante ou muito importante para a maioria dos alunos (56\%). Fator semelhante, o trancamento total ou parcial de disciplinas, igualmente, figurou como fator de atraso na graduação, apontado como importante ou muito importante por $42 \%$ dos discentes. A pesquisa de Coelho et al. (2013) evidencia que a reprovação em disciplinas foi o principal motivo para a retenção dos alunos de Administração da Universidade Federal da Paraíba (UFPB).

O Gráfico 3 apresenta os fatores da retenção dos alunos de Administração da ufs e seus respectivos índices.

Gráfico 3 Fatores condicionantes da retenção

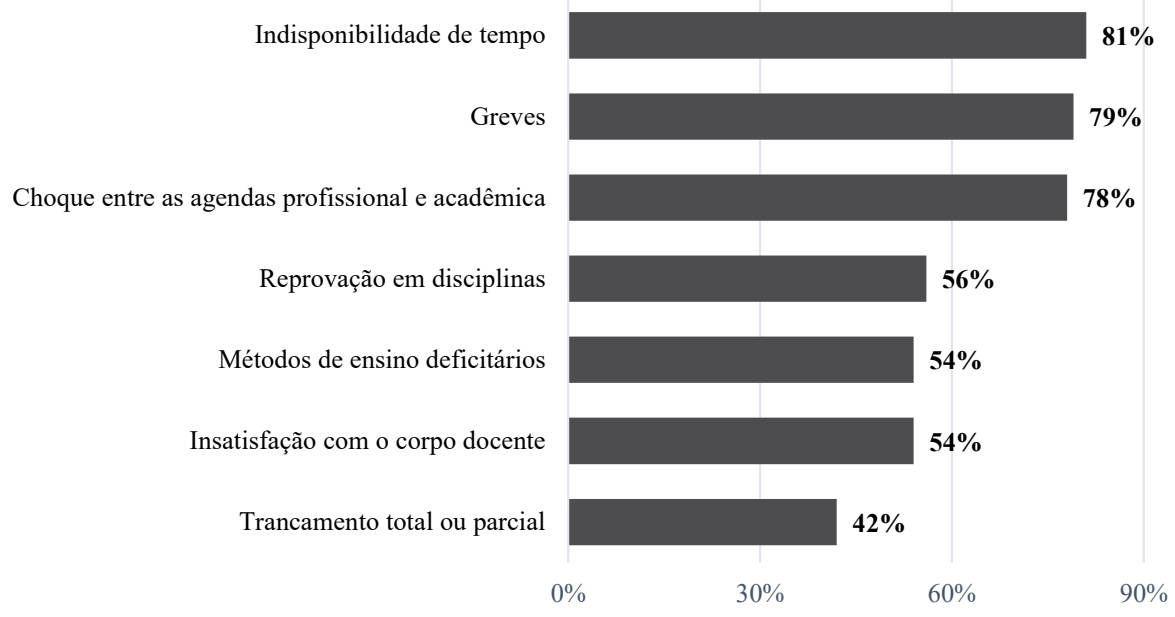

A partir dessas constatações, fica claro o impacto que os fatores pessoais, especialmente o trabalho, exercem na vida acadêmica do aluno de Administração. Cabe-lhes, portanto, uma tomada de decisão entre a carreira e a graduação, em que, muitas vezes, aquela é mais valorizada. 
No entanto, em algum momento, o diploma de Administrador tornarse-á imprescindível para o desenvolvimento profissional, fato que deve ser fortemente considerado pelo graduando.

Porém os motivos institucionais, como greves, insatisfação com o corpo docente e métodos de ensino deficitários, também, afetam a evolução acadêmica, desse modo, desmotivando os alunos e não atendendo suas expectativas.

\section{AÇÕES DE ESTÍMULO À CONCLUSÃO REGULAR DESENVOLVIDAS PELO DAD}

As informações obtidas com os gestores e ex-gestores do DAD objetivaram conhecer suas opiniões e as ações de combate à retenção por eles desenvolvidas.

Sobre as causas da retenção, os docentes concentraram suas respostas na entrada do aluno no mercado de trabalho e na ausência do jubilamento na UFS. Para eles, ao iniciar a carreira, o aluno deixa a graduação em segundo plano, especialmente quando se destaca no trabalho. Sobre a não aplicação do jubilamento, os docentes afirmaram que tal fato proporciona aos discentes um contexto favorável ao atraso do curso, visto que não há risco de perda de vínculo devido à sua longa permanência na universidade. Quando o aluno exerce atividades remuneradas, tal situação se agrava, pois esse não será afetado econômica ou socialmente.

Os gestores do DAD afirmaram que existe uma tendência à retenção no curso de Administração, especialmente, devido à estrutura do mercado de trabalho da área. A não exigência do diploma de Administrador por algumas empresas ocasiona a postergação da formatura, uma vez que os alunos não veem a conclusão do curso como um pré-requisito para exercer suas atividades. Tal fato não ocorre em áreas mais consolidadas, como Medicina e Engenharias, segundo os docentes.

A respeito do acompanhamento da retenção pelo DAD, os docentes responderam, tanto com relação às suas gestões quanto à atual, que esse tem sido realizado de forma parcial. Discorreram, ainda, que o DAD necessita que suas ações tenham apoio e legitimação da Reitoria e dos conselhos 
superiores, que são os órgãos decisores sobre os assuntos estudantis. Uma ação comum à maioria das gestões foi a elaboração de planos curriculares individuais para os alunos, objetivando a inserção e adequação das disciplinas pendentes, buscando a conclusão do curso no menor tempo possível.

Os docentes sugeriram ações de combate à retenção, assim, citando o jubilamento e a construção de uma relação mais próxima do DAD junto aos alunos. Para eles, o jubilamento é positivo para a instituição, visto que sua efetivação ocasionaria um maior comprometimento dos alunos para a conclusão no tempo regular, melhorando os índices acadêmicos da UFS. Quanto à abordagem do DAD junto aos alunos, recomendaram que esta seja mais humanística e individualizada, levantando as causas da retenção e dando continuidade à construção dos planos de conclusão do curso formatados para as diferentes demandas dos alunos.

Outras medidas foram sugeridas, a exemplo da mudança do curso matutino para noturno; pagamento de bolsa aos alunos cotistas, com metas a cumprir e aumento da oferta de ações de pesquisa e extensão.

Em suma, a visão institucional dos docentes contribuiu para melhor entender o problema da retenção. No tocante ao mercado profissional, deve haver um amadurecimento sobre a questão da flexibilização da contratação de não diplomados no exercício das funções de administrador. Quanto à uFs, faz-se necessário que enxergue, com mais sensibilidade, o quão negativa é a permanência prolongada dos discentes, colocando em pauta a discussão sobre a efetivação do jubilamento. 


\section{CONSIDERAÇÕES FINAIS}

Diante dos resultados alcançados pelo presente estudo, foi possível individuar os alunos retidos do curso de Administração; perceber o nível de qualidade do curso, atribuído pelos alunos; entender que fatores os levam a atrasar o curso e, por fim, conhecer o ponto de vista dos docentes sobre o problema, bem como suas ações de minimização da retenção.

Nesse ponto, é importante ressaltar a descoberta, pelo presente estudo, de um fator condicionante da retenção não indicado pela bibliografia do tema: as greves. Segundo principal motivo para a retenção apontado nos resultados, elas se colocam como mais um obstáculo para a conclusão regular a ser gerido pela comunidade acadêmica. Assim, esta pesquisa contribui para a revisão bibliográfica da retenção, ao apontar mais um fator a ser considerado pelos estudos da área.

Diante de tais resultados, torna-se possível, para a UFS e o DAD, tomarem ciência da ocorrência e do contexto da retenção. Tais informações podem contribuir na formulação de estratégias para que os alunos atrasados concluam o curso o mais rápido possível, bem como evitar que outros se tornem retidos.

A retenção é, sem dúvida, um problema que afeta tanto os discentes quanto as IES. Os primeiros, por postergarem a conclusão do curso, não obtendo o diploma de administrador, fato que os privam de galgar melhores espaços no mercado de trabalho. Para as IEs, a retenção se apresenta como um fator negativo no conjunto de indicadores de qualidade de ensino, desse modo, revelando o quão tardio pode ser o processo de formatura em determinado curso.

Isso posto, é imprescindível que ambos os atores da problemática da retenção se unam e tomem iniciativas para a resolução de tal situação. Os alunos procurando adequar os fatores pessoais e externos da retenção, avaliando o trabalho e a carga horária que desempenham; dedicando mais tempo aos estudos; planejando sua evolução acadêmica, a partir da montagem de grades curriculares a médio e longo prazo, além de evitarem a reprovação e o trancamento de disciplinas. 
Já a UFS, mormente o DAD, deve atentar para os motivos institucionais da retenção. Como ações preventivas/corretivas, tem-se: criação de mecanismos eficientes de composição do quadro de docentes; análise crítica das avaliações de docentes feitas pelos alunos; maior oferta de disciplinas que atendam à demanda; construção de planos de evolução acadêmica para os alunos retidos; levantamento individualizado dos motivos da retenção e reformulação das ementas de algumas disciplinas. Essa última, objetivando maior espaço para a prática de gestão, inclusive com maior promoção de visitas técnicas, aulas práticas, ações de extensão e projetos de pesquisa no curso de Administração.

Ressalta-se que o presente estudo teve como objetivo conhecer os pontos de vista dos discentes e docentes de Administração da ufs acerca do problema da retenção. Obteve-se, portanto, um conjunto de informações oriundo exclusivamente do Departamento de Administração.

Como sugestão para pesquisas futuras, recomenda-se ampliar as unidades de análise, ouvindo os conselhos superiores das IEs sobre a retenção, especialmente, acerca da questão do jubilamento como forma de garantia da conclusão no tempo regular. Outra questão pode ser a comparação entre os cursos das Ciências Sociais Aplicadas, dessa forma, objetivando entender aos diferentes contextos do mercado profissional de cada área e como eles afetam o tempo de conclusão do curso. 


\section{REFERÊNCIAS}

ALENCAR, L. M. B. A evasão discente no contexto da Reestruturação Universitária: o caso dos cursos de Administração e Ciências Contábeis da UFES. 2014. $205 \mathrm{fls}$. Dissertação (Mestrado Profissional em Gestão Pública) - Programa de Pós-Graduação em Gestão Pública, UFES, Vitória, 2014.

MELLO, S. P. T. de; DINIZ, R. M.; KRUGER JUNIOR, P. R.; SANTOS, E. G.; BARBOSA, L. P.; NEUENFELDT, C. S. Pesquisando causas e possíveis soluções para a problemática da evasão em um curso de Administração numa universidade pública no Sul do Brasil. In: CIGU, 11., 2011, Florianópolis. Anais eletrônicos... Florianópolis: UFSC, 2011.

BIAZUS, C. A. Sistema de fatores que influenciam o aluno a evadir-se dos cursos de graduação na UFSM e na UFSC: um estudo no curso de Ciências Contábeis. 2004. 203fls. Tese (Doutorado em Engenharia de Produção) - Programa de Pós-Graduação em Engenharia de Produção, UFSC, Florianópolis, 2004.

CAMPELLO, A. V. C.; LINS, L. N. Metodologia de análise e tratamento da evasão e retenção em cursos de graduação de instituições federais de ensino superior. In: ENEGEP, 28.. 2008, Rio de Janeiro. Anais eletrônicos... Rio de Janeiro: ABEPRO, 2008. Disponível em: < http:/ / bit.ly/29rzwGh>. Acesso em: maio/2015.

CORRÊA, A. C. C.; NORONHA, A. B.; SANTOS, F. F. F. Avaliação do tempo de titulação dos alunos atualmente matriculados e a relação do prolongamento de curso com a questão da evasão para o curso de Administração da FEA/USP. ANGRAD, v. 4, n.1, p. 24-40, 2003.

COELHO, K. S. et al. Uma reflexão sobre a atuação da coordenação na retenção de discentes: o caso do curso de Administração do campus I da Universidade Federal da Paraíba. In: CIGU, 13.. 2013, Buenos Aires. Anais eletrônicos... Florianópolis: UFSC, 2013.

\section{COMISSÃO ESPECIAL DE ESTUDOS SOBRE A EVASÃO NAS UNIVERSIDADES PÚBLICAS BRASILEIRAS. ANDIFES / ABRUEM/SESu/MEC. Diplomação, retenção e evasão nos cursos de graduação em IES Públicas. Out. 1996.}

CUNHA, J. V. A.; DURSO, S. O.; NASCIMENTO, E. M. Razões e influências para a evasão universitária: um estudo com estudantes ingressantes nos cursos de Ciências Contábeis de instituições públicas federais da Região Sudeste. In: CONGRESSO USP DE CONTROLADORIA E CONTABILIDADE, 14. 2014, São Paulo. Anais eletrônicos... São Paulo: USP, 2014.

CUNHA, J.V.A.; DE LUCA, M.M.M.; LIMA, G.A.S.F.; Cornacchione Jr., E.B.; OTT, E. Quem está ficando para trás? Uma década de Evasão nos cursos brasileiros de Graduação em Administração de Empresas e Ciências Contábeis. REPeC, v. 9, n. 2, art. 1, p. 124-142, 2015.

DIAS, E. C. M.; LOPES, M. A. S.; THEÓPHILO, C. R. Evasão no ensino superior: estudo dos fatores causadores da evasão no curso de Ciências Contábeis da UNIMONTES. In: 
CONGRESSO USP DE INICIAÇÃO CIENTÍFICA EM CONTABILIDADE, 7., 2010, São Paulo. Anais eletrônicos... São Paulo: USP, 2010.

FIALHO, M. G. D.; PFEIFFER, D. K.; PRESTES, E. M. T. A evasão no Ensino Superior globalizado e suas repercussões na gestão universitária. In: ENCONTRO INTERNACIONAL DA SOCIEDADE BRASILEIRA DE EDUCAÇÃO COMPARADA, 6. 2014, Bento Gonçalves. Anais eletrônicos... Bento Gonçalves: SBEC, 2014.

GAIOSO, N. P. L. O fenômeno da evasão escolar na educação superior no Brasil. 2005. 75 fls. Dissertação (Mestrado em Educação) - Programa de Pós-Graduação em Educação da Universidade Católica de Brasília, Brasília, 2005.

INEP. Censo da Educação Superior. Brasília: INEP, 2013.

PEREIRA JÚNIOR, E. Compromisso com o graduar-se, com a instituição e com o curso: estrutura fatorial e relação com a evasão. 2012. 89fls. Dissertação (Mestrado em Educação) - Programa de Pós-Graduação da Faculdade de Educação. UNICAMP, Campinas, 2012.

POLYDORO, S. A. J. O trancamento de matrícula na trajetória acadêmica do universitário: condições de saída e de retorno à instituição. 2000. 175fls. Tese (Doutorado em Educação) - Programa de Pós-Graduação da Faculdade de Educação. UNICAMP, Campinas, 2000.

SAUBERLICH, K. C. H. C. Fatores que produzem evasão acadêmica no curso de Ciências Contábeis da UNEMAT de Tangará da Serra/MT. Revista UNEMAT de Contabilidade, v. 1, n. 2, p. 158-180, 2012.

SILVA FILHO, R. L. L. INEP está retomando seu caminho? Estadão, São Paulo, nov. 2014. Disponível em: <http:/ / bit.ly/2b7EeaF> . Acesso em: maio/2015.

SILVA FILHO, R. L. L.; MOTEJUNAS, P.R.; HIPÓLITO, O.; LOBO, M.B.C.M. Evasão no Ensino Superior Brasileiro. Cadernos de Pesquisa, v. 37, n. 132, p. 641-659, 2007.

SILVA, M. N.; VASCONCELOS, A. L. S. Uma investigação sobre os fatores contribuintes na retenção dos alunos de Ciências Contábeis em uma IFES: um desafio à gestão universitária. Registro Contábil, v. 2, n. 3, p. 21-34, 2011.

TINTO, V. Classrooms as communities: exploring the educational character of student persistance. The Journal of Higher Education, v. 68, n. 6, p. 599-623, 1997.

TINTO, V. Reconstructing the first year of college. Planning for Higher Education, v. 25, n. 1, p. 1-6, 1996.

TINTO, V.; CULLEM, J. Dropout in higher education: a review and theoretical synthesis of recent research. Review of Educational Research, v. 45, n. 1, p. 89-125, 1975.

UFS. COGEPLAN. Relatório de Gestão 2014. São Cristóvão: UFS, 2015.

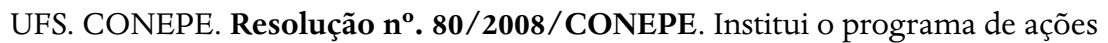
afirmativas para o acesso de grupos menos favorecidos à UFS. São Cristóvão: UFS, 2008.

UFS. COPAC. Anuário estatístico da UFS: 2011-2013. São Cristóvão: UFS, 2013. 
RETENÇÃO DOS DISCENTES DE ADMINISTRAÇÃO DA UFS: FATORES CONDICIONANTES E AÇÕES DA GESTÃO ACADÊMICA

UFS. COPAC. Anuário estatístico da UFS: 2009-2011. São Cristóvão: UFS, 2011.

VERGARA, S. C. Projetos e relatórios de pesquisa em Administração. 2.ed. São Paulo: Atlas, 1998.

YIN, R. K. Estudo de caso: planejamento e métodos. 2.ed. Porto Alegre: Bookman, 2001. 


\section{DADOS DOS AUTORES}

RODRIGO TELES DANTAS DE OLIVEIRA^ oliveira.rtd@gmail.com Bacharel em Administração pela UFS

Instituição de vinculação: Universidade Federal de Sergipe São Cristóvão/SE - Brasil

Áreas de interesse em pesquisa: Estratégia, Administração Pública e Gestão da Educação.

*Av. Marechal Rondon, S/N Jardim Rosa Elze São Cristóvão/SE 49100-000

JENNY DANTAS BARBOSA jennyufs@gmail.com

Doutora em Administração pela Universidad Complutense de Madrid

Instituição de vinculação: Universidade Federal de Sergipe

Aracajú/SE - Brasil

Áreas de interesse em pesquisa: Estratégia, Microempresas e Gestão Ambiental. 